\title{
Brazilian consensus in enuresis-recomendations for clinical practice
}

José Murillo B. Netto ${ }^{1}$, Atila Victal Rondon ${ }^{2}$, George Rafael Martins de Lima ${ }^{3}$, Miguel Zerati Filho ${ }^{4}$, Edison Daniel Schneider-Monteiro ${ }^{5}$, Carlos Augusto F. Molina ${ }^{6}$, Adriano de Almeida Calado ${ }^{7}$, Ubirajara Barroso Jr. ${ }^{8}$

${ }^{1}$ Universidade Federal de Juiz de Fora (UFJF) e Hospital e Maternidade Therezinha de Jesus da Faculdade de Ciências Médicas e da Saúde de Juiz de Fora (HMTJ-SUPREMA), Juiz de Fora, MG, Brasil; ${ }^{2}$ Universidade do Estado do Rio de Janeiro (UERJ) e Hospital Federal Cardoso Fontes (HFCF), Rio de Janeiro, RJ, Brasil; ${ }^{3}$ Hospital Infantil Albert Sabin, Fortaleza, CE, Brasil; ${ }^{4}$ Instituto de Urologia e Nefrologia de São José do Rio Preto (IUN) e Faculdade Regional de Medicina(FAMERP), Hospital de Base, São José do Rio Preto, SP, Brasil; ${ }^{5}$ Hospital da Pontifícia Universidade Católica de Campinas (PUC-Campinas), Campinas, SP, Brasil; ${ }^{6}$ Hospital das Clinicas da Faculdade de Medicina de Ribeirão Preto da Universidade de São Paulo (HCFMRP-USP), Ribeirão Preto, SP, Brasil $;{ }^{7}$ Faculdade de Medicina da Universidade de Pernambuco (UPE), Recife, PE, Brasil ; ${ }^{8}$ Universidade Federal da Bahia (UFBA) e Escola Bahiana de Medicina (BAHIANA), Salvador, BA, Brasil

\section{ABSTRACT}

Introduction: Enuresis, defined as an intermittent urinary incontinence that occurs during sleep, is a frequent condition, occurring in about 10\% of children at 7 years of age. However, it is frequently neglected by the family and by the primary care provider, leaving many of those children without treatment. Despite of many studies in Enuresis and recent advances in scientific and technological knowledge there is still considerable heterogeneity in evaluation methods and therapeutic approaches.

Materials and Methods: The board of Pediatric Urology of the Brazilian Society of Urology joined a group of experts and reviewed all important issues on Enuresis and elaborated a draft of the document. On September 2018 the panel met to review, discuss and write a consensus document.

Results and Discussion: Enuresis is a multifactorial disease that can lead to a diversity of problems for the child and family. Children presenting with Enuresis require careful evaluation and treatment to avoid future psychological and behavioral problems. The panel addressed recommendations on up to date choice of diagnosis evaluation and therapies.

\section{ARTICLE INFO}

José Murillo B. Netto

http://orcid.org/0000-0002-9959-6160

\section{Keywords:}

Enuresis; Urinary Incontinence; Lower Urinary Tract Symptoms

Int Braz J Urol. 2019; 45: 889-900

Submitted for publication:

February 04, 2019

Accepted after revision:

May 06, 2019

Published as Ahead of Print:

July 15, 2019

\section{INTRODUCTION}

Enuresis is defined as an intermittent urinary incontinence that occurs during sleep, having clinical significance after the child completes 5 years of age (1). It is a frequent condition, occurring in about 15 to $20 \%$ of 5 years old children and 6.4 to $10.3 \%$ of children at 7 years of age (2-4) with a spontaneous re- 
solution rate of about 15\% per year (5) and will still be presented in approximately 0.5 to $2.3 \%$ of adults $(6,7)$.

Enuresis is a multifactorial condition. Hereditary factors have been described and genetic factors are the most important in the etiology of enuresis (8). Family history of enuresis plays important rule. Studies have shown a risk of a child have enuresis to be $44 \%$ if one parent was enuretic and 77\% if both had enuresis, and 15\% if neither one of the parents suffered from the disorder (9).

Other factors involved on enuresis physiopathology are changes in bladder function (nocturnal bladder overactivity) (10), nocturnal urinary output (nocturnal polyuria due to altered circadian cycle of the antidiuretic hormone) (11-13) and associated with disturbance of awakening (inability of the child to wake up in response to bladder contractions or full bladder sensation) $(14,15)$.

There is evidence that enuresis is associated with emotional and behavioral changes (16), dysfunctions of the urinary and intestinal tracts (17), and respiratory changes, such as nocturnal apnea (18-20).

About 20 to 30\% of enuretic children present with psychological/psychiatric disorders (2 to 4 times more than non-enuretic ones) (21). Enuretic children present more behavioral problems than non-enuretic ones regarding to social and attention problems (22).

Many enuretic children will present emotional and/or behavioral changes, such as sadness, mood alteration, shame, low self-esteem, feelings of guilt, insecurity, social isolation, low school performance, among others (21). In addition, families are also affected and the consequences of enuresis, for both the child and his family, are often neglected. Recent studies have shown significant loss of quality of life, not only for children, but also for their families $(23,24)$. Thus, parents, by not well understanding the problem and also for being stressed often become intolerant and punishing the child. Two national studies have shown a high incidence of punishment in enuretic children, being it verbal, physical without contact (chastisement) or with contact (aggression) $(25,26)$.

When relevant emotional and behavioral changes are identified, especially in secondary enuresis, psychological evaluation and treatment are recommended.

Enuresis can be classified according to the moment of its appearance and to the symptoms presented and both classifications should be added to define the correct type of enuresis (Figure-1).

Evaluating the outcome of a treatment is important for clinical and research purpose. The

Figure 1 - Classification of Enuresis.

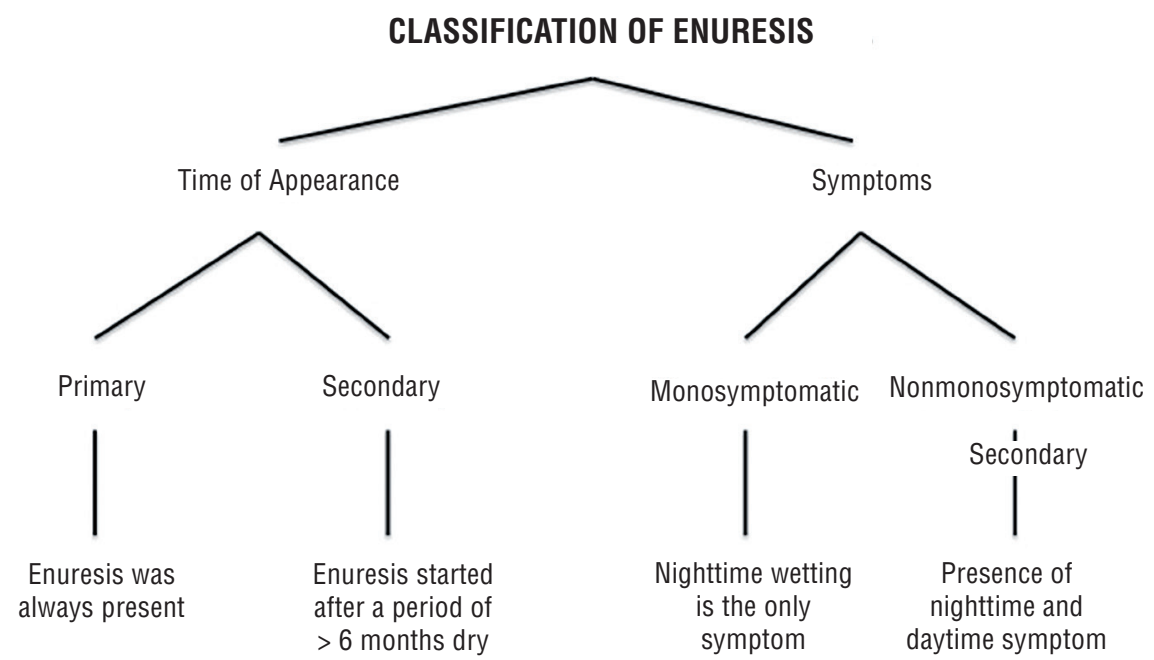


standardization document from ICCS considers treatment outcome as "No Response when there is an improvement of less than 50\% of the symptoms, "Partial Response" when there is improvement of 50 to 99\% of the symptoms and "Complete Response" when $100 \%$ of the symptoms are resolved. Relapse is considered when more than one episode occurs per month. Continuous Success is when there is absence of relapse in 6 months and Complete Success when no relapses occur after 2 years (27).

\section{MATERIALS AND METHODS}

The board of Pediatric Urology of the Brazilian Society of Urology, noticing the need of a Brazilian guideline on Enuresis, joined a group of experts to review the important issues on Enuresis and elaborated a consensus document. Eight renewed pediatric urologist with known experience in dealing with voiding dysfunction and enuresis were invited to participate in the elaboration a document with the scope of the guiding urologists, pediatricians, nephrologists and all others that deal with enuresis on the most important and up to date aspects of the evaluation and treatment of enuretic children.

All panel members were instructed to perform a literature search on MEDLINE, EMBASE and COCHRANE LIBRARY databases as well as review of the base of practical guidelines database for the last 20 years using the terms "Enuresis", "Nocturnal Enuresis", and "Bedwetting". Papers were selected according to their level of evidence, giving more importance to meta-analysis, systematic reviews, and randomized controlled trials. Criterion of exclusion of bibliography included topics in which neither of those were found or were not of good quality or did not address treatment options. Cohort and series of patients were used to add information. Review papers and guidelines were used as orientation for which topics and aspects would be included.

After the papers were selected, each member of the group were designated one topic to review and write an orientation document based on the recommended literature.

On September 2018, all members joined together during 2 days to review and discuss the previous written documents of each topic and prepare the consensus document. Further discussions, corrections, and revisions were carried out digitally, until all members of the panel have approved this final document. A paragraph containing the panels opinion ("consensus") was added at the end of each section to guide the reader about the information provided and the most common practice on that subject.

\section{CLINICAL EVALUATION AND DIAGNOSIS}

A careful and meticulous clinical history is the best tool to understand and diagnose the correct type of enuresis and propose the most appropriate treatment. For this, it is necessary to differentiate between primary or secondary, and mono or non-monosymptomatic enuresis.

Anamnesis should include the child's age, if any dry period had occurred, presence of voiding symptoms throughout the day (incontinence, increased voiding frequency, urinary urgency and low volume voiding), bowel habits, number of enuresis episodes per night and per week, information on child's sleep pattern, sleep apnea, and difficulties in awakening, presence of any behavioral problem, such as attention deficit and hyperactive disorder (ADHD), anxiety, stress, abuse, bullying (28) and punishment (25). Past and familial histories are also important.

A careful history of bowel habits should be included to investigate constipation. The use of Rome IV criteria and Bristol Stool Scale is recommended to help making the proper diagnosis. In cases when the child presents signs of increase urine output diabetes mellitus should be investigated (glycosuria and glycaemia) and excluded.

Physical exam is helpful in identifying associated comorbidities. Genitalia should be careful examined and also abdomen, where signs of constipation (impacted feces in the left colon) can be found. Examination of the back is important to exclude any cutaneous sign of occult spinal cord malformation (29). As a complement to the clinical history, the child should be asked to complete both a voiding and a night diary. The voiding diary increases the reliability of the information gi- 
ven by the family and makes the parents aware of their child voiding habits. It should be performed for two to three days, not necessarily consecutive, and include all void and drink episodes. The voiding diary collects information on frequency, time of void, volume at each micturition, episodes of urgency and/or incontinence, liquid intake. It is considered normal 4 to 7 void per day, and an average of voided volume between 65 and 150\% of the expected bladder capacity for the age, calculated by the formula ((Age+1) x 30) (27). A carefully orientation, explaining any doubts, on how to fulfill the voiding diary is important to avoid problems in its outcome.

A dry night diary of 14 consecutive days should also be obtained with the purpose of recording the frequency that enuresis occurs. To obtain the night-voided volume, the child is asked to sleep wearing a diaper. The sum of the diaper's weight $(\mathrm{Kg})$, the voided volume of the first micturition, and the voided volume of any episode of nocturia, if present will give the nocturnal diuresis. Night polyuria is considered to be a nocturnal diuresis volume $>130 \%$ estimated bladder capacity or $>$ the volume expressed by the formula ((age+9) x 20) (27).

No other test is necessary in the evaluation of monosymptomatic enuresis. Children with polyuria and polydipsia should be investigated for diabetes insipidus.

Evaluation of non-monosymptomatic enuresis will be discussed at the end of the document.

Consensus: The panel believes that a careful and meticulous clinical history considering all aspects discussed above, associated with a voiding diary are the most important tools in the evaluation of an enuretic child. It is important to address all behavioral problems the child may have. The addition of any other diagnostic test is rarely necessary in children with monosymptomatic enuresis.

\section{TREATMENT (Figure-2)}

\section{Urotherapy \\ Urotherapy or behavioral therapy consists in a series of orientations indicated as initial treatment}

in all patients with enuresis it should be maintained throughout the treatment even when other therapeutic modalities are chosen $(27,30)$. The aims of urotherapy are to inform and demystify enuresis and give orientation on habits modifications to improve symptoms.

Urotherapy orientation includes (27, 31): 1) information and demystification. Explanation about the normal function of the urinary tract and how that particular child deviates from the normal pattern; 2) regular voiding habits (voiding every 3 to 4 hours); 3) avoid retention maneuvers; 4) appropriate voiding position on the toilet to promote relaxation of the pelvic floor (appropriate-sized seat, footrest, forward bending of the torso); 5) regular bowel habits (standard time for evacuation, preferably after meals); 6) increase fluid intake during the day, specially in the mornings and early afternoon; 7) change dietary habits (eliminate caffeine, avoid citric fruits and juices, reduce sodium intake at nigh); 8) avoid any liquids at least 2 hours before bedtime; 9) void prior to go to bed; 10) no use of diapers; 11) dry nights calendar; and 12) support and encouragement through regular follow-up with the child and caregiver, providing positive reinforcement (award system for dry nights).

Behavioral interventions were superior when compared to no intervention, but had worse results when used alone to treat associated with alarm or drug therapy $(32,33)$. The resolution rate of enuresis with urotherapy alone is about 20\% (34).

Consensus: The panel agrees that urotherapy orientations should be offered to any child with enuresis as first line treatment, regardless if it is mono or non-monosymptomatic. The health professional should provide clear information and reinforce all orientation given in every clinical consult. The addition of other therapeutic modalities will increase success of urotherapy.

\section{Enuresis Alarm}

The Enuresis Alarm is an electronic device that uses a humidity sensor placed at underwear and connected to a sound and/or vibrating circuit that will be activated when the child wets the bed. The purpose of the alarm is to wake the child up during the enuretic episode and make the user (or a responsible person) go to the toilet to com- 
Figure 2 - Treatment Algorithm.

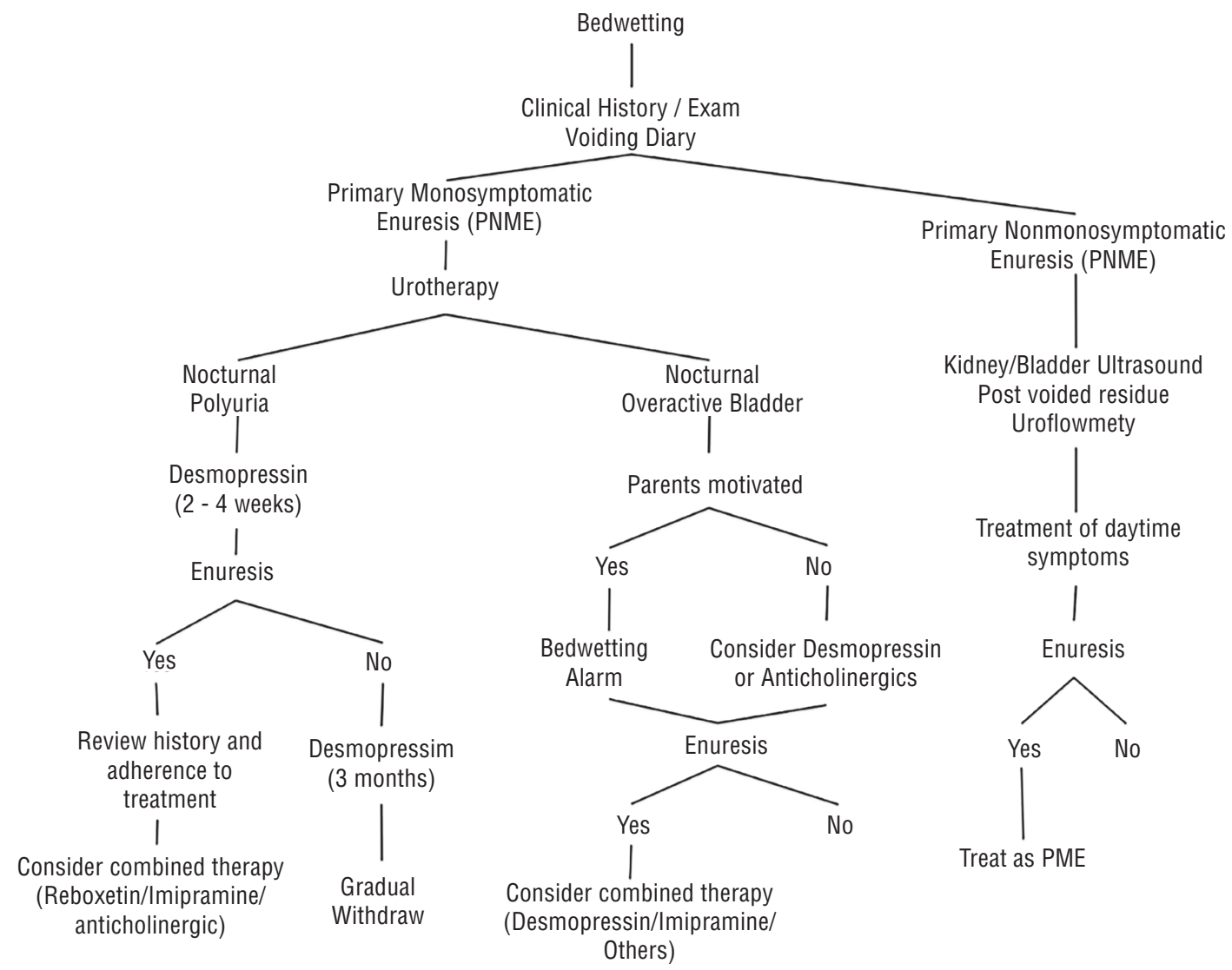

plete micturition. It is considered as behavioral or conditioning treatment. The age recommended to start treatment with alarm is six to seven years when the child is mature enough to accept and understand the treatment (35).

The alarm is considered the most effective long-term treatment for enuresis (Level of evidence and recommendation 1A). Results suggest a success rate of 62 to $75 \%$ after treatment, with a relapse rate of 15 to 30\% during long-term follow-up (36-38).

The greatest problem with enuresis alarm is that a high number of patients discontinue treatment (30\% to 50\%) due to loss of motivation or other factors, such as waking up other members of the family during the night and the duration of the treatment that may take about six to eight weeks $(38,39)$. Due to this, a supportive approach to the family is necessary to reduce these numbers (35).

Results with alarm therapy improves if urine volume is greater than or equal to $65 \%$ of the expected capacity for age, in children who have more number of wet nights (40), and when parents and child are motivated (34). Factors related to failure of poor results are punitive parental reactions to the bedwetting (41), child behavioral problems, higher socioeconomic status (41), and if treatment is started out of the winter (41).

It is recommended that the child should keep using the alarm after 14 consecutive dry nights before stopping treatment.

Alarm should not be indicated when punishment is identified and should be used with caution in cases of night sweats in hot climate areas, due to activation of the alarm by humidity caused by sweat, and when the child sleeps with other children and a risk of bullying exists.

Compared to desmopressin, studies suggest that enuresis alarm is better in the long run, but some show that results may equivalent if the 
highest alarm dropout rate is considered $(35,39)$.

The addition of desmopressin to alarm treatment improves dry nights rate initially, but in the long term there is no benefit with this addition. Therefore, there is no recommendation that these methods be used together except in cases that fail when either one is used alone (42).

Treatment with alarm is better than oxybutynin alone and the addition of oxybutynin to the alarm does not improve the success rate in the initial treatment. This association is only indicated in refractory cases (43). Alarm was shown to be better than imipramine in improving the number of dry nights (44).

Regarding the two types of alarm, the body-worn alarm and the bed pad alarm, the alarm fixed on the body is preferred by the children (44). There is no evidence on which type of alarm is better than the other. Further studies need to be performed.

Consensus: The panel highly recommends the use of alarm in children with primary monosymptomatic enuresis that presents with a high number of wet nights and parents are motivated. A careful evaluation of the child and family, discarding behavioral problems and punishment is important for treatment success. Alarm treatment should be followed closely due to a high number of children that discontinue treatment. When no or poor response is found, other drugs such as desmopressin may be added to the treatment.

\section{Desmopressin}

Desmopressin acetate is a synthetic analogue of the natural hormone, arginine vasopressin (antidiuretic hormone). It acts increasing the reabsorption of water through the renal tubules, leading to an increase in urinary osmolality and decreased diuresis $(45,46)$.

Desmopressin is a first-line treatment for enuresis with grade $1 \mathrm{~A}$ of evidence. Its best results can be obtained in children with nocturnal polyuria (diuresis $>130 \%$ estimated bladder capacity or $>$ (age +9 ) $\times 20 \mathrm{~mL}$, adding the volume of the furst void in the morning) (27) and normal bladder reservoir function (maximum voided volume greater than $70 \%$ of estimated bladder capacity for age)
(47), and children with a greater age, and limited number of wet nights a week $(31,46)$.

Its administration is orally and should be taken one hour prior to bedtime and about 2 hours after dinner. It is recommended to start with a low dose of 0.1 to $0.2 \mathrm{mg}$ and adjust, when necessary, up to a maximum dose of $0.6 \mathrm{mg} /$ day, regardless of age or weight (48). One hour before taking the medication, children should stop fluid intake in order to avoid risk of hyponatremia and water intoxication, as well as obtain an optimal urine concentrating capacity (49).

Initial treatment should be maintained for 2 to 4 weeks in order to obtain maximum effect and if there is improvement in the number of dry night it should be continued for at least 3 more months. If the child is dry, withdrawn of the medication may be done gradually, which seems to reduce relapse $(48,49)$. In cases when symptoms worsen after beginning medication withdraw, dose should be increased again and treatment maintained for three more months.

The overall success rate of desmopressin is up to $65 \%$ and the relapse rate, especially if a gradual withdraw is not done, goes up to $80 \%$ (50). However, the outcome is lower in the long term follow-up.

Consensus: The panel believes that desmopressin should be used as first line treatment for all children with nocturnal polyuria and those that the use of enuresis alarm is not suitable. Dose should be increased gradually until dryness is achieved and treatment maintained for at least 3 months. There is evidence that withdrawn should be done gradually. Parents and child should be aware that, although rare, increase fluid intake and desmopressin may lead to side effects (hyponatremia and water intoxication).

\section{Other Drugs}

\section{Anticholinergics}

The use of anticholinergics in enuresis is limited (grade 1B evidence) $(51,52)$. Children with increased voiding frequency and low bladder volume ( $<65 \%$ of estimated bladder capacity) and with nocturnal bladder overactivity are the most suitable candidates as anticholinergics act inhi- 
biting bladder contractions. The most commonly used anticholinergic in our setting is oxybutynin, although others such as solifenacine, and tolterodine can be used.

The results with anticholinergics in enuresis, although better than placebo, are poor when used as monotherapy and they should only be indicated if other treatments have failed (31). In these cases, anticholinergics can be helpful in up to $40 \%$ of the patients, especially in combination with desmopressin (53).

The major problem with the use of anticholinergics is, in addition to bad results, that a significant amount of patients present side effects, such as constipation, increased post-voided residual, dry mouth, among others. Therefore, when using anticholinergic drugs, constipation should first be assessed (53).

Consensus: In the panel's opinion, anticholinergics should be used only in cases where no success with desmopressin and alarm was achieved and in selected patients with overactive bladder. Evaluation of constipation and post-voided residual should be done prior to prescription.

\section{Tricyclic Antidepressants}

The leading tricyclic antidepressant prescribed for enuresis is imipramine. Randomized trials have shown that imipramine is slightly better than placebo, but due to safety concerns (cardiotoxicity) and side effects, it is considered to be a third line treatment for enuresis (Grade 1C evidence) (54-56), and should only be used in cases of failure of the first therapeutic options or when patients cannot afford them.

The mechanism of action of tricyclic antidepressants in enuresis is still controversial. It is known that they decrease the amount of time spent in REM sleep, stimulate vasopressin secretion, and relax the detrusor muscle.

Imipramine has shown to be more effective particularly for short-term outcomes, with fewer wet nights per week when compared to placebo $(54,57)$. Imipramine promotes a reduction of 1 wet night per week, with about $20 \%$ of children being dry for at least 14 consecutive nights. However, no sustained results are seen after ceasing treatment, and the majority of patients relapse af- ter discontinuation of treatment (54).

Combination therapy including imipramine and anticholinergics showed improved results when compared to imipramine alone or placebo in the short and long term, with fewer relapses than imipramine monotherapy $(54,58)$. The combination of tricyclic antidepressants and desmopressin did not show any improvement in treatment results $(54,59)$.

It is advised to take the medicine $1 \mathrm{~h}$ before bedtime, in the initial dosage of $10-25 \mathrm{mg}$, and it can be increased in $25 \mathrm{mg}$ after 1 week of treatment. The maximum dose in children aged 6-12 years is $50 \mathrm{mg} /$ day and in those over 12 years of age up to $75 \mathrm{mg} /$ day. Every 3 months, treatment should be discontinued for at least 2 weeks to decrease the risk of drug tolerance and observation of therapeutic efficacy.

Imipramine presents limitations due to its cardiotoxicity with potential risk of cardiac conduction disorders and myocardial depression in overdose. Other possible side effects are possible behavioral changes, irritability and drowsiness, dizziness, headache, sweating, lethargy, sleep disturbance or restlessness, apathy, depression, among others.

Consensus: It is the panel's opinion that imipramine and other tricyclic antidepressants should be reserved to those that failed other treatment. It should be used with caution and the family should be aware of possible side effects and the medication should be kept away from child's reach. Due to its low cost compared to other treatment modalities, it can be an option in patients with low income. Combination with anticholinergics should be in mind to improve results.

\section{Alternative Treatments}

So-called alternative, or rather unconventional, treatments such as acupuncture, hypnosis, homeopathy, herbalism, chiropractic, faradization, among others, have been tested but there is no scientific evidence to support their use.

The results with neuromodulation (transcutaneous electroneurostimulation) are controversial, and there may be a reduction in dry nights but no complete response in primary monosymptomatic enuresis. Further studies are need to validate its use in enuresis (60). 
Consensus: The panelists agree that alternative treatment should not be used, except for electroneurostimulation, that could be tried in cases in which other therapies have failed.

\section{THERAPY RESISTANT ENURESIS}

Some patients will not respond to alarm nor desmopressin and those are considered the therapy resistant ones, and, for them, other therapeutic modalities should be tried.

Assessment of these children includes a careful clinical history and physical exam trying to identify any missed information in their previous evaluation and treatment (49).

Possible factors related to poor therapeutic response should be careful investigated prior to considering the child resistant to treatment (61). Some questions should be addressed, such as: 1) is enuresis really monosymptomatic or daytime symptoms are present?; 2) does the patient present nocturnal polyuria?; 3) is the child reducing/stopping fluid intake at least 2 hours prior to bedtime; 4 ) is he/she following dietary orientation (low caffeine and citric intake)?; 5) is desmopressin being taking as prescribed ( 1 hour before bedtime and 2 hours after dinner)?; 6) is desmopressin dose adequate or it can be raised?; 7) is the alarm being used correctly?; 8) is there any behavioral disorder, such as attention deficit and hyperactivity disorders or others?

Children not responding to enuresis alarm correctly should be reinforced and reoriented on how the alarm works and how to be used and, those not motivated, other therapeutic options, such as desmopressin or other drugs should be started.

In desmopressin resistant patients, possible causes are excess urine solute due to increased sodium intake or altered sodium circadian rhythm or influence of vasoactive hormones and prostaglandins, such as renin, aldosterone and atrial natriuretic peptide. After defining the patient as resistant to desmopressin, we can divide them among those with absence of response despite decreased diuresis and those with nocturnal bladder overactivity as a possible etiology (61).

Therapeutic options for desmopressin resistant children includes indomethacin, a cycloo- xygenase inhibitor, although significantly reduces nocturnal sodium, urea and osmotic excretion, no significant decrease in the number of wet nights was observed neither as mono therapy nor as combined to desmopressin $(62,63)$.

Furosemide has also been tried as a second line treatment for those resistant to desmopressin. It should be taken in the morning to increase diuresis and excretion of sodium and solutes during the day and, when associated to desmopressin, it has shown decrease of frequency of enuresis (64).

Reboxetine, an antidepressant with noradrenergic action, significantly reduced enuresis episodes in therapy resistant patients when compared to placebo, although must of the responses were partial (65).

Combination therapy is an option in those patients. The combined use of desmopressin and an anticholinergic agent is well tolerated and results in a significant improvement in enuresis episodes and the results suggest a better response if higher anticholinergic dose is used (up to 10mg) $(66,67)$. The effect of combined therapy of desmopressin and alarm is still controversial and immediate positive effect has been presented (68, $69)$, although some have lacked to show long term effect (42).

Consensus: It is the panel's opinion that therapy resistant enuresis should always be addressed by an experienced professional in the field, since those cases requires expertise due to its complexity and poor results with the current available treatment options. A careful clinical history and physical exam are keys to achieve success in those cases.

\section{NON-MONOSYMPTOMATIC ENURESIS}

Non-monosymptomatic nocturnal enuresis (NME) is characterized by the presence of diurnal symptoms associated with enuresis and is present in about $1 / 3$ of all enuretic children (70). It has peculiarities that differ it from the monosymptomatic enuresis, as increased risk of urinary tract infection and greater association with constipation and emotional/behavioral disorders.

Those children with NME need proper evaluation and treatment. Greater attention should be 
taken on diurnal voiding symptoms (urgency, frequency, incontinence, straining to void) and constipation. Besides the voiding diary, evaluation of the post-void urinary residue by ultrasound and uroflowmetry are required to make the correct diagnosis and propose the ideal treatment. Assessment of bowel function with Rome IV criteria and Bristol Stool Scale should be careful evaluated as those children frequently present constipation.

Initial treatment should address daytime symptoms first focusing on treating the lower urinary tract dysfunction, constipation, and any behavioral disorder if present (1).

Urotherapy is the initial therapy and should be performed for at least one month. In the persistence of symptoms, more specific treatments are indicated and added to urotherapy. Therapeutic options include anticholinergics, alpha-blockers, electro neurostimulation, biofeedback, and botulin toxin.

Children who do not improve diurnal and nocturnal symptoms should continue with other therapeutic modalities that remain focused on the treatment of daytime symptoms such as increased dose of medication or combination of medications and of medication with other therapies (electro neurostimulation or biofeedback). Constipation, when present, should be assessed in the beginning of treatment. Improvement of bowel habits is a key point for improvement of voiding function.

If enuresis is still persistent after improvement of daytime symptoms; its treatment follows those described for monosymptomatic enuresis.

Consensus: The panel believes that children presenting with non-monosymptomatic enuresis should be evaluated as those presenting lower urinary tract dysfunction, which includes voiding diary, uroflowmetry and ultrasound with evaluation of post-voided residual. Assessment of constipation and behavioral disorders should not be forgotten during clinical investigation and should be treated if present. Daytime symptoms are the focus of the initial therapy and enuresis is treated after improvement of daytime lower urinary tract symptoms.

\section{CONFLICT OF INTEREST}

None declared.

\section{REFERENCES}

1. Franco I, von Gontard A, De Gennaro M; International Childrens's Continence Society. Evaluation and treatment of nonmonosymptomatic nocturnal enuresis: a standardization document from the International Children's Continence Society. J Pediatr Urol. 2013;9:234-43.

2. Fergusson DM, Horwood LJ, Shannon FT. Factors related to the age of attainment of nocturnal bladder control: an 8-year longitudinal study. Pediatrics. 1986;78:884-90.

3. Hellström AL, Hanson E, Hansson S, Hjälmås K, Jodal U. Micturition habits and incontinence in 7-year-old Swedish school entrants. Eur J Pediatr. 1990;149:434-7.

4. Järvelin MR, Vikeväinen-Tervonen L, Moilanen I, Huttunen NP. Enuresis in seven-year-old children. Acta Paediatr Scand. 1988;77:148-53.

5. Feehan M, McGee R, Stanton W, Silva PA. A 6 year followup of childhood enuresis: prevalence in adolescence and consequences for mental health. J Paediatr Child Health. 1990;26:75-9.

6. Hirasing RA, van Leerdam FJ, Bolk-Bennink L, Janknegt RA. Enuresis nocturna in adults. Scand J Urol Nephrol. 1997;31:533-6.

7. Yeung CK, Sihoe JD, Sit FK, Bower W, Sreedhar B, Lau J. Characteristics of primary nocturnal enuresis in adults: an epidemiological study. BJU Int. 2004;93:341-5.

8. von Gontard A, Schaumburg H, Hollmann E, Eiberg $H$, Rittig S. The genetics of enuresis: a review. J Urol. 2001;166:2438-43.

9. Bakwin, H.: The Genetics of Enuresis. In: Bladder Control and Enuresis. Edited by I. M. Kolvin, R. C.; Meadow, S. R. London: William Heinemann Medical Books, 1973.

10. Yeung CK, Sit FK, To LK, Chiu HN, Sihoe JD, Lee E,et al. Reduction in nocturnal functional bladder capacity is a common factor in the pathogenesis of refractory nocturnal enuresis. BJU Int. 2002;90:302-7.

11. Rittig S, Schaumburg HL, Siggaard C, Schmidt F, Djurhuus JC. The circadian defect in plasma vasopressin and urine output is related to desmopressin response and enuresis status in children with nocturnal enuresis. J Urol. 2008;179:2389-95. 
12. Aikawa $T$, Kasahara $T$, Uchiyama M. The argininevasopressin secretion profile of children with primary nocturnal enuresis. Eur Urol. 1998;33(Suppl 3):41-4.

13. Dossche L, Walle JV, Van Herzeele C. The pathophysiology of monosymptomatic nocturnal enuresis with special emphasis on the circadian rhythm of renal physiology. Eur J Pediatr. 2016;175:747-54.

14. Yeung CK, Diao M, Sreedhar B. Cortical arousal in children with severe enuresis. N Engl J Med. 2008;358:2414-5.

15. Hunsballe JM. Increased delta component in computerized sleep electroencephalographic analysis suggests abnormally deep sleep in primary monosymptomatic nocturnal enuresis. Scand J Urol Nephrol. 2000;34:294-302.

16. Von Gontard A, Hollmann E. Comorbidity of functional urinary incontinence and encopresis: somatic and behavioral associations. J Urol. 2004;171(6 Pt 2):2644-7.

17. Hoffmann A, Sampaio C, Nascimento AA, Veiga ML, Barroso $U$. Predictors of outcome in children and adolescents with overactive bladder treated with parasacral transcutaneous electrical nerve stimulation. J Pediatr Urol. 2018;14:54.e154.e6.

18. Dahan P, de Bessa J Jr, de Oliveira DM, Gomes CC, Cardoso JC, Macedo IT, de Almeida Belo M, de Figueiredo AA, Netto JM. Association between Asthma and Primary Nocturnal Enuresis in Children. J Urol. 2016;195(4 Pt 2):1221-6.

19. Sousa AS, Veiga ML, Braga AA, Carvalho MC, Barroso U $\mathrm{Jr}$. Enuresis and overactive bladder in children: what is the relationship between these two conditions? Int Braz J Urol. 2016;42:798-802.

20. Sampaio C, Sousa AS, Fraga LG, Veiga ML, Bastos Netto JM, Barroso U Jr. Constipation and Lower Urinary Tract Dysfunction in Children and Adolescents: A PopulationBased Study. Front Pediatr. 2016;4:101.

21. von Gontard A, Baeyens D, Van Hoecke E, Warzak WJ, Bachmann C. Psychological and psychiatric issues in urinary and fecal incontinence. J Urol. 2011;185:1432-6.

22. Akyüz M, Koca O, Karaman B, Özcan ZY, Öztürk M , Kutluhan $M A$, et al. Evaluation of behavioral problems in patients with monosymptomaticnocturnal enuresis: a prospective controlled trial. Turk J Med Sci. 2016;46:807-11.

23. Van Herzeele C, Dhondt K, Roels SP, Raes A, Groen LA, Hoebeke $P$, et al. Neuropsychological functioning related to specific characteristics of nocturnal enuresis. J Pediatr Urol. 2015;11:208.e1-6.

24. Kilicoglu AG, Mutlu C, Bahali MK, Adaletli H, Gunes H, Duman HM, et al. Impact of enuresis nocturna on healthrelated quality of life in children and their mothers. J Pediatr Urol. 2014;10:1261-6.
25. Sá CA, Gusmão Paiva $A C$, de Menezes MC, de Oliveira LF, Gomes CA, de Figueiredo AA, et al. Increased Risk of Physical Punishment among Enuretic Children with Family History of Enuresis. J Urol. 2016;195(4 Pt 2):1227-30.

26. Sapi MC, Vasconcelos JS, Silva FG, Damião R, Silva EA. Assessment of domestic violence against children and adolescents with enuresis. J Pediatr (Rio J). 2009;85:433-7.

27. Austin PF, Bauer SB, Bower W, Chase J, Franco I, Hoebeke $P$, et al. The standardization of terminology of lower urinary tract function in children and adolescents: Update report from the standardization committee of the International Children's Continence Society. Neurourol Urodyn. 2016;35:471-81.

28. Akan S, Ürkmez A, Yildirim C, Sahin A, Yüksel ÖH, Verit A. Late-onset secondary nocturnal enuresis in adolescents associated with post-traumatic stress disorder developed after a traffic accident. Arch Ital Urol Androl. 2015;87:250-1.

29. Haid B, Tekgül S. Primary and Secondary Enuresis: Pathophysiology, Diagnosis, and Treatment. Eur Urol Focus. 2017;3(2-3):198-206.

30. Maternik M, Krzeminska K, Zurowska A. The management of childhood urinary incontinence. Pediatr Nephrol. 2015;30:41-50.

31. Neveus T, Eggert P, Evans J, Macedo A, Rittig S, Tekgül S, et al. Evaluation of and treatment for monosymptomatic enuresis: a standardization document from the International Children's Continence Society. J Urol. 2010;183:441-7.

32. Glazener CM, Evans JH, Peto RE. Complex behavioural and educational interventions for nocturnal enuresis in children. Cochrane Database Syst Rev. 2004;(1):CD004668.

33. Hjalmas K, Arnold T, Bower W, Caione P, Chiozza LM, von Gontard A, et al. Nocturnal enuresis: an international evidence based management strategy. J Urol. 2004;171(6 Pt 2):2545-61.

34. Devlin JB, O'Cathain C. Predicting treatment outcome in nocturnal enuresis. Arch Dis Child. 1990;65:1158-61.

35. Perrin N, Sayer L, While A. The efficacy of alarm therapy versus desmopressin therapy in the treatment of primary mono-symptomatic nocturnal enuresis: a systematic review. Prim Health Care Res Dev. 2015;16:21-31.

36. Houts AC, Berman JS, Abramson H. Effectiveness of psychological and pharmacological treatments for nocturnal enuresis. J Consult Clin Psychol. 1994;62:737-45.

37. Butler RJ, Robinson JC. Alarm treatment for childhood nocturnal enuresis: an investigation of within-treatment variables. Scand J Urol Nephrol. 2002;36:268-72.

38. Butler RJ, Gasson SL. Enuresis alarm treatment. Scand J Urol Nephrol. 2005;39:349-57. 
39. Evans J, Malmsten B, Maddocks A, Popli HS, Lottmann $\mathrm{H}$; UK study group. Randomized comparison of long-term desmopressin and alarm treatment for bedwetting. J Pediatr Urol. 2011;7:21-9.

40. Jensen IN, Kristensen G. Alarm treatment: analyses of response and relapse. Scand J Urol Nephrol Suppl. 1999;202:73-5.

41. Moffatt ME, Cheang M. Predicting treatment outcome with conditioning alarms. Scand J Urol Nephrol Suppl. 1995;173:119-22.

42. Ozden C, Ozdal OL, Aktas BK, Ozelci A, Altinova S, Memis $A$. The efficacy of the addition of short-term desmopressin to alarm therapy in the treatment of primary nocturnal enuresis. Int Urol Nephrol. 2008;40:583-6. Erratum in: Int Urol Nephrol. 2008;40:587.

43. Yucel S, Kol A, Guntekin E, Baykara M. Anticholinergics do not improve cure rate of alarm treatment of monosymptomatic nocturnal enuresis. Urology. 2011;77:721-4.

44. Glazener CM, Evans JH, Peto RE. Alarm interventions for nocturnal enuresis in children. Cochrane Database Syst Rev. 2005;(2):CD002911.

45. Alloussi SH, Mürtz G, Lang C, Madersbacher H, Strugala $\mathrm{G}$, Seibold J, et al. Desmopressin treatment regimens in monosymptomatic and nonmonosymptomatic enuresis: A review from a clinical perspective. J Pediatr Urol. 2011;7:1020.

46. Tauris LH, Andersen RF, Kamperis K, Hagstroem S, Rittig $S$. Reduced anti-diuretic response to desmopressin during wet nights in patients with monosymptomatic nocturnal enuresis. J Pediatr Urol. 2012;8:285-90.

47. Rushton HG, Belman AB, Zaontz MR, Skoog SJ, Sihelnik $S$. The influence of small functional bladder capacity and other predictors on the response to desmopressin in the management of monosymptomatic nocturnal enuresis. J Urol. 1996;156(2 Pt 2):651-5.

48. Sinha R, Raut S. Management of nocturnal enuresis - myths and facts. World J Nephrol. 2016;5:328-38.

49. Vande Walle J, Rittig S, Bauer S, Eggert P, Marschall-Kehrel D, Tekgul S; et al. European Society for Paediatric Urology; European Society for Paediatric Nephrology; International Children's Continence Society. Practical consensus guidelines for the management of enuresis. Eur $\mathrm{J}$ Pediatr. 2012;171:971-83. Erratum in: Eur J Pediatr. 2013;172:285. Eur J Pediatr. 2012;171:1005.

50. Keatin JC Jr. Functional nocturnal enuresis. J Manipulative Physiol Ther. 1995;18:44-6.
51. KoŞar A, Arikan N, Dinçel C. Effectiveness of oxybutynin hydrochloride in the treatment of enuresis nocturna--a clinical and urodynamic study. Scand J Urol Nephrol. 1999;33:115-8.

52. Austin PF, Ferguson G, Yan Y, Campigotto MJ, Royer ME, Coplen DE. Combination therapy with desmopressin and an anticholinergic medication for nonresponders to desmopressin for monosymptomatic nocturnal enuresis: a randomized, double-blind, placebo-controlled trial Pediatrics. 2008;122:1027-32.

53. Nevéus T, Läckgren G, Tuvemo T, Olsson U, Stenberg A. Desmopressin resistant enuresis: pathogenetic and therapeutic considerations. J Urol. 1999;162:2136-40.

54. Caldwell PH, Sureshkumar P, Wong WC. Tricyclic and related drugs for nocturnal enuresis in children. Cochrane Database Syst Rev. 2016;(1):CD002117.

55. Glazener CM, Evans JH, Peto RE. Tricyclic and related drugs for nocturnal enuresis in children. Cochrane Database Syst Rev. 2003;(3):CD002117.

56. Gepertz S, Nevéus T. Imipramine for therapy resistant enuresis: a retrospective evaluation. J Urol. 2004;171(6 Pt 2):2607-10.

57. Nevéus T, Tullus K. Tolterodine and imipramine in refractory enuresis; a placebo-controlled crossover study. Pediatr Nephrol. 2008;23:263-7.

58. Tahmaz L, Kibar Y, Yildirim I, Ceylan S, Dayanç M. Combination therapy of imipramine with oxybutynin in children with enuresis nocturna. Urol Int. 2000;65:135-9.

59. Burke JR, Mizusawa Y, Chan A, Webb KL. A comparison of amitriptyline, vasopressin and amitriptyline with vasopressin in nocturnal enuresis. Pediatr Nephrol. 1995;9:438-40.

60. de Oliveira LF, de Oliveira DM, da Silva de Paula LI, de Figueiredo AA, de Bessa J Jr, de Sá CA, et al. Transcutaneous parasacral electrical neural stimulation in children with primary monosymptomatic enuresis: a prospective randomized clinical trial. J Urol. 2013;190:1359-63.

61. Kamperis K, Van Herzeele C, Rittig S, Vande Walle J. Optimizing response to desmopressin in patients with monosymptomatic nocturnal enuresis. Pediatr Nephrol. 2017;32:217-226.

62. Kamperis K, Rittig S, Bower WF, Djurhuus JC. Effect of indomethacin on desmopressin resistant nocturnal polyuria and nocturnal enuresis. J Urol. 2012;188:1915-22.

63. Kamperis K, Hagstroem S, Faerch M, Mahler B, Rittig S, Djurhuus JC. Combination treatment of nocturnal enuresis with desmopressin and indomethacin. Pediatr Nephrol. 2017;32:627-633. 
64. De Guchtenaere A, Vande Walle C, Van Sintjan P, Donckerwolcke R, Raes A, Dehoorne J, Van Laecke E, Hoebeke P, Vande Walle J. Desmopressin resistant nocturnal polyuria may benefit from furosemide therapy administered in the morning. J Urol. 2007;178:2635-9.

65. Lundmark E, Stenberg A, Hägglöf B, Nevéus T. Reboxetine in therapy-resistant enuresis: A randomized placebo-controlled study. J Pediatr Urol. 2016;12:397.e1-397.e5.

66. Berkenwald A, Pires J, Ellsworth P. Evaluating use of higher dose oxybutynin in combination with desmopressin for refractory nocturnal enuresis. J Pediatr Urol. 2016;12:220.e1-6.

67. Chua ME, Silangcruz JM, Chang SJ, Yang SS. Immediate 1-month efficacy o desmopressin and anticholinergic combination therapy versus desmopressin monotherapy in the treatment of pediatric enuresis: A meta-analysis. J Pediat Urol. 2016;12:156.e1-9.

68. Vogt M, Lehnert T, Till H, Rolle U. Evaluation of different modes of combined therapy in children with monosymptomatic nocturnal enuresis. BJU Int. 2010;105:1456-9.
69. Leebeek-Groenewegen A, Blom J, Sukhai R, Van Der Heijden B. Efficacy of desmopressin combined with alarm therapy for monosymptomatic nocturnal enuresis. J Urol. 2001;166:2456-8.

70. Butler RJ, Golding J, Northstone K; ALSPAC Study Team. Nocturnal enuresis at 7.5 years old: prevalence and analysis of clinical signs. BJU Int. 2005;96:404-10.

\section{Correspondence address:}

José Murillo B. Netto, MD

Universidade Federal de Juiz de Fora (UFJF) and

Hospital e Maternidade Therezinha de Jesus da

Faculdade de Ciências Médicas e da Saúde de Juiz de Fora (HMTJ-SUPREMA)

Av. Rio Branco, 2985/605 Juiz de Fora, MG, 36010-012, Brasil

E-mail: jose.murillo@ufjf.edu.br 